\title{
Hazards of Chronic Exposure to Nonylphenol: Concomitant Effect on Non-alcoholic Fatty Liver Disease in Male Albino Rats
}

\author{
Rania Elsyade $^{1}$ (D), Eman El Sawaf ${ }^{1}$ (D), Dalia Gaber ${ }^{2 *}$ (iD \\ ${ }^{1}$ Department of Anatomy and Embryology, Faculty of Medicine, Helwan University, Cairo, Egypt; ${ }^{2}$ Department of Medical \\ Biochemistry and Molecular Biology, Faculty of Medicine, Helwan University, Cairo, Egypt
}

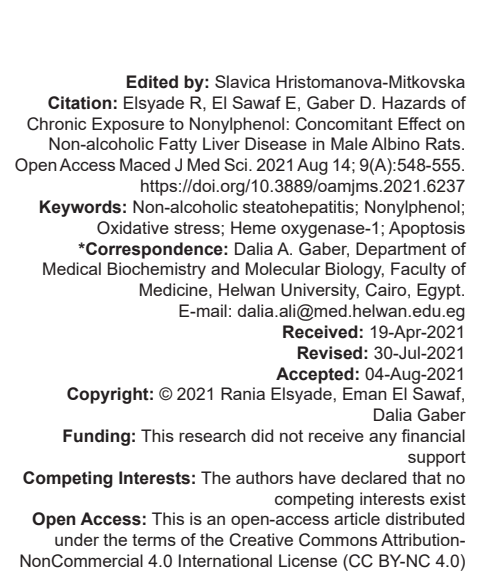

\section{Introduction}

Chronic liver disease is a major health problem, with non-alcoholic fatty liver disease (NAFLD) being the most prevalent cause worldwide. This condition is precipitated by excess deposition of triglycerides (TGs) inside hepatocytes and is commonly associated with metabolic syndrome [1]. Prevalence rates range from $25 \%$ to $45 \%$, according to age, gender, ethnic group, and methods used for diagnosis [2], [3].

Genetic and environmental factors are the main contributors to the pathogenesis of NAFLD. Unbalanced bad diet habits and lack of physical activity are among the main precipitating factors [4]. Recently, several pieces of research have pointed to endocrine disruptors (EEDs) such as nonylphenol (NP), and their potential effect on the increased incidence of NAFLD [5].

NP is a well-known environmental endocrinedisrupting chemical with weak estrogenic activity [6]. It is used in detergents, emulsifiers, and in several industries, for example in paints, pesticides, and household toiletries [7]. Studies have suggested that NP has deleterious effects on the endocrine [8], reproductive [9], immune [10], and nervous systems in animals and humans [11].

Recent studies have indicated that exposure to EEDs is associated with an increased risk of metabolic disorders [12]. Such as steatosis [13], obesity [14], insulin resistance [15], and type 2 diabetes [16]. Previous studies tested the oxidative stress induced by various doses of NP and the resulting hepatotoxicity [17], [18], [19].

Another study tested hepatotoxicity due to chronic exposure to a daily dose of $180 \mathrm{mg} / \mathrm{kg} /$ day [20] and doses of $0.02,0.2,2 \mu \mathrm{g} / \mathrm{kg} /$ day [21] of NP, and its effect on NAFLD. To our knowledge, no study tested the chronic exposure to an intermediate dose of NP and its synergistic effect on NAFLD.

Herein, in this study, we investigated the effect of exposure to a $20 \mu \mathrm{g} / \mathrm{kg}$ daily dose of NP, its effect on the expression of oxidative stress genes heme oxygenase $1(H \operatorname{mox} 1)$, and its role in inducing non-alcoholic steatohepatitis (NASH) when administered with high sucrose-high-fat diet (HSHFD). 


\section{Materials and Methods}

\section{Animals and experimental design}

Forty adult male albino rats (100-150 g) were prepared from the animal house at the Experimental Animal Research Unit at the Faculty of Medicine Ain Shams Research institute of the Faculty of Medicine, Ain Shams University, Cairo, Egypt. The rats were housed in animal cages under the prevailing atmospheric conditions and given access to tap water and libitum. The rats were divided into four groups ( $n=10 /$ group). The HSHFD group was fed a diet rich in carbohydrates and fats. The NP group received a daily oral intake of NP in olive oil $(20 \mu \mathrm{g} / \mathrm{kg} / \mathrm{day})$ for 60 days. The NP + HSHFD group received a HSHFD with NP administration. The control group received the vehicle only (olive oil). We purchased NP from Sigma Aldrich, the USA with a purity $>99 \%$.

The experiments were carried out in accordance with the guidelines for the Care and Use of Lab Animals, Faculty of Medicine, Ain shams University. It was approved by the Experimental Animal Research Unit of MASRI, Ain Shams University on 17/11/2019, number 0413088, documented by FMASU REC R05 2021, Federal wide assurance number FWA 000017585 .

\section{Biochemical analyses}

Blood samples $(10 \mathrm{ml})$ were collected from the abdominal aorta on day 60 for the biochemical studies. The samples were centrifuged at $4,000 \mathrm{rpm}$ for $10 \mathrm{~min}$ and the sera were stored at $-20^{\circ} \mathrm{C}$ until testing. Total cholesterol (TC) was measured using TC Assay Kits, cat no: STA-384, serum TG was measured using Total TGs assay kit, cat no: STA-396 and highdensity lipoprotein cholesterol (HDL-C) was measured using HDL-C Assay Kit, cat no: STA-394. Serum levels of alanine aminotransferase (ALT) and aspartate aminotransferase (AST) were measured using ALT Activity Assay Kit (Colorimetric), cat no: MET-5123, and AST Assay Kit respectively, cat no: MET-5127 (CELL BIOLABS, INC, Creating Solutions for life Science Research).

\section{Tissue collection}

The rats were anesthetized on day 60 using sodium thiopental and then sacrificed. The liver tissue of each rat was divided into two portions. One portion was placed in phosphate-buffered saline (PBS) and RNA later (Qiagen, Germany) and stored at $-80^{\circ} \mathrm{C}$ for further processing. The other portion was immediately preserved in $10 \%$ neutral buffered formalin for histopathology and immunohistochemistry evaluation.

\section{Studying the oxidative stress status on exposure to NP and HSHFD}

Hmox1 expresses heme oxygenase 1 $(\mathrm{HO}-1)$ and is one of the genes involved in oxidative stress in rat liver [12]. Quantitative assessment of Hmox1 expression was performed by real-time polymerase chain reaction (PCR).

\section{Tissue homogenization}

The tissue samples were suspended in a $2.0 \mathrm{~mL}$ screw-cap tube, containing $200 \mathrm{uL}$ of PBS. Then, a single $5 \mathrm{~mm}$ stainless steel bead (Qiagen) was added to each tube, and the samples were homogenized at maximum speed ( 30 Hertz) for 2 min using the Qiagen Tissue-Lyser system. Following homogenization, the samples were spun for 1 min at maximum speed to reduce foaming. Then, the homogenate was applied to the filter column for RNA extraction.

\section{Total RNA extraction and purification}

Total RNA was extracted using the RNeasy Mini Kit; cat no: 217004 (Qiagen, Hilden, Germany) according to the manufacturer's protocol.

\section{Reverse transcription}

cDNA was synthesized by reverse transcription reaction using QuantiTect Reverse Transcription Kit; cat no: 205311; (Qiagen, Hilden, Germany).

\section{Gene expression analysis}

The quantification of HO-1 was amplified from mRNA using a Quanti Tect primer assay primer assays; (HMOX1_1_SG QuantiTect Primer Assay; cat no: 249900, assay ID: QT00092645 and the QuantiTect SYBR Green PCR.

All samples were analyzed using the 5 plex Rotor-Gene PCR Analyzer (Qiagen, Germany). The $2 \Delta \Delta \mathrm{Ct}$ method was conducted for the analysis of gene expression levels, using ACTB as an endogenous reference control for normalization purposes.

\section{Histopathology and immunohistochemistry}

Autopsy samples were taken from the liver of rats in the different groups and fixed in $10 \%$ neutral buffered formalin for $24 \mathrm{~h}$. Then, the samples were washed in tap water and dehydrated in serial dilutions of alcohol (methanol, ethanol, and absolute ethanol) were used for dehydration. The samples were cleared in xylene and embedded in paraffin at $56^{\circ} \mathrm{C}$ in a hot air oven for $24 \mathrm{~h}$. Paraffin-beeswax tissue blocks were 
prepared, and 4- $\mu \mathrm{m}$ thick sections were cut using a sledge microtome. The obtained tissue sections were collected on glass slides, deparaffinized, and stained by using hematoxylin and eosin ( $\mathrm{H}$ and $\mathrm{E}$ ) for examination using light microscopy [22].

Immunohistochemical staining was performed on 4- $\mu \mathrm{m}$, formalin-fixed, paraffin-embedded sections. The caspase 3 antibodies were used as 1:50 dilution (DAKO, Carpinteria, CA). The slides were then heated using a 1-mmol/L EDTA solution of $\mathrm{pH} 8.0$ for $30 \mathrm{~min}$. Using an automated immunostainer (DAKO), staining was performed after blocking the endogenous biotin. For each assay performed, positive and negative control sections were used [23].

\section{Statistical analysis}

The sample size was calculated using the Raosoft sample size calculator (http://www.raosoft.com/ samplesize.html), and all statistical calculations were performed using SPSS v26.0 statistical software (IBM Corp). at probability levels of $0.05,0.01$, and 0.001 [24]. (Snedecor and Cochran, 1980). Quantitative data with parametric distribution was assessed using oneway analysis of variance followed by post-hoc analysis using Fisher's exact test for comparisons between the three groups. Quantitative data with non-parametric distribution were analyzed using the Kruskal-Wallis test to compare the three groups. Graphs were constructed using GraphPad Prism 8 (GraphPad Software, USA). $A$ heat map correlation analysis was performed to estimate the relationship between quantitative parameters [25].

\section{Results}

\section{Biochemical analyses}

The levels of plasma ALT and AST showed a highly statistically significant difference between the studied groups ( $p<0.001$; Figure $1 A$ and $B$ ). Ingestion of a HSHFD, NP, and exposure to both NP and HSHFD significantly increased raised both AST and ALT plasma levels compared with the control group. The highest AST levels were observed in the NP + HSHFD group (Figure 1A).

Regarding the lipid profile, there was marked elevation of serum cholesterol, TG, and low-density lipoprotein cholesterol (LDL-C) in the HSHFD, NP + HSHFD, and NP groups compared with the control group with $(p<0.001$; Figure $1 C-E)$, with highest in the NP + HSHFD group. The NP + HSHFD showed the lowest level of serum HDL-C, but this was not significantly different from the control group (Figure $1 \mathrm{~F}$ ).

\section{Gene expression of Hmox1 in liver tissue}

The gene expression of Hmox 1 in liver tissue was highly significantly enhanced in the NP + HSHFD and HSHFD groups in comparison with the control group $(p<0.001)$, with the highest relative quantification value in the NP + HSHFD group (Figure 2a). However, there was no significant difference between the control and NP groups.

Analysis of the correlation between the level of Hmox 1 expression and the laboratory data of the studied groups revealed a weak positive correlation with serum cholesterol, TG, and LDL-C and a strong

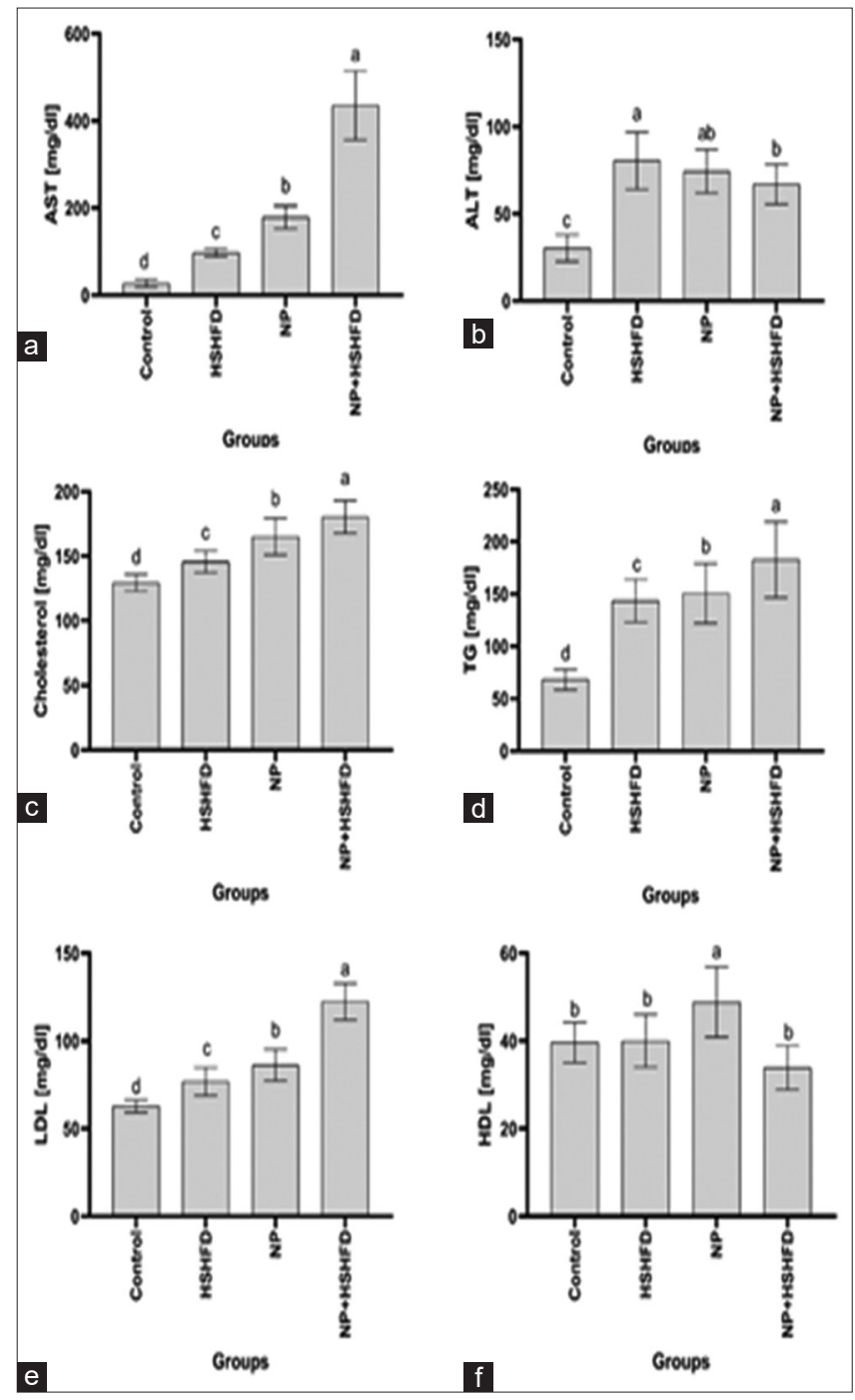

Figure 1: Comparisons of plasma transaminases lipid profile among the experimental groups ( $n=10 /$ group). The letters ( $a, b, c$ and d) indicate significant difference of $p \leq 0.05$ between groups. (A) Comparison of AST levels between control, HSHFD, NP and $N P+H S H F D$ groups. F-value $=268.46, p<0.001$. (B) Comparasion of ALT levels between control, HSHFD, NP, and NP+HSHFD groups. $F$-value $=49.88, p<0.001$. (C) Comparsion of TC levels between control, HSHFD, NP, and NP+HSHFD groups. F-value $=64.02$, $p<0.001$. (D) Comparsion of TG levels between control, HSHFD, NP, and NP+HSHFD groups. F-value $=53.77, p<0.001$. (E) Comparsion of LDL-C between control, HSHFD, NP, and NP+HSHFD groups. F-value $=146.94, p<0.001$. (F) Comparsion of HDL-C between control, HSHFD, NP, and NP+HSHFD groups. F-value $=8.02$, $p<0.001$. HSHFD: High source-high-fat diet; NP: Nonylphenol 


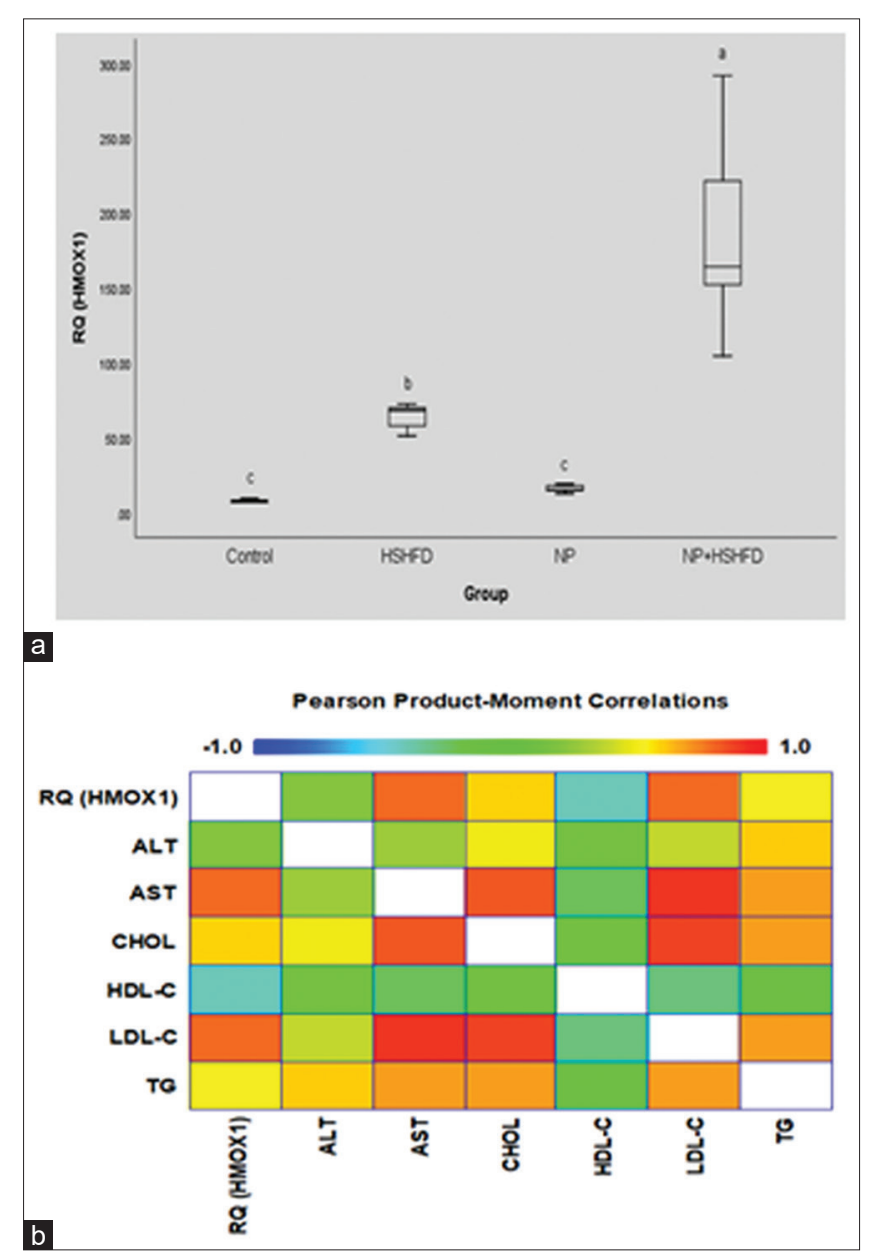

Figure 2: Expression of Hmox1 mRNA in rat liver tissue of the studied groups ( $n=10 /$ group). (a) Hmox1 is significantly increased in the $N P+H S H F D$ and HSHFD groups in comparison with the control group $(p<0.0001)$, with the highest relative RQ in the NP+HSHFD group. No significant difference is noted between the control and NP groups. The letters ( $a, b, c$ and $d)$ indicate significant differences of $p \leq 0.05$ between groups. Kruskal-Wallis $=55.49, p<0.001$. HSHFD: High sucrose-high-fat diet; NP: Nonylphenol; RQ: relative quantification value. (b) Pearson correlation between Hmox1 expression level, lipid profile and plasma transaminases. A week positive correlation is noted between Hmox1 and serum TC, TG, LDL-C, while a strong positive correlation is noted between Hmox1 and plasma AST. A negative correlation is noted between Hmox1 expression and plasma HDL-C. RQ: Relative quantification value; $C H O L$ : Cholesterol

positive correlation with plasma AST. A negative correlation was noted between Hmox1 expression and plasma HDL (Figure 2b).

\section{Histopathology and immunohistochemistry}

The liver sections stained with $\mathrm{H}$ and $\mathrm{E}$ were examined using a light microscope. There was no histopathological alteration in the control samples. Normal histological structure of the central vein and surrounding hepatocytes in the lobular parenchyma, as well as the portal area with portal vein, hepatic artery and bile ducts, were recorded (Figure 3a and $b$ ). In the HSHFD group, fatty changes were noted in the hepatocytes and dilatation in the central vein all over the hepatic parenchyma (Figure $3 c$ and $d$ ). The NP group revealed pale large nucleolus, cytoplasmic vacuoles, with focal lymphoid cells aggregation in the hepatic parenchyma and dilatation in the central veins (Figure $4 a$ and $b$ ). In the NP + HSHFD group, severe dilatation and congestion were detected in both central and portal veins. The portal area showed a massive number of inflammatory cells infiltration and congestion in the portal vein. There were hyperplasia and dilatation in the bile ducts at the portal area as well as multiple newly formed bile ductules, congestion in the portal vein, and degeneration in the surrounding hepatocytes in the parenchyma (Figure 4c-e).

The immunostaining reaction by inactive caspase -3 showed negative expression in the control group, HSHFD group, and NP group but strong marked expression was observed in the NP + HSHFD group (Figure 5 and Table 1).

Table 1: Immuno-histopathological staining for caspase-3 expression in the liver tissue of different groups

\begin{tabular}{|c|c|c|c|c|}
\hline Study group & Control & HSHFD & $\mathrm{NP}$ & $\mathrm{NP}+\mathrm{HSHFD}$ \\
\hline $\begin{array}{l}\text { Caspase }-3 \\
\text { expression }\end{array}$ & $\begin{array}{l}\text { Negative } \\
\text { expression }\end{array}$ & $\begin{array}{l}\text { Negative } \\
\text { expression }\end{array}$ & $\begin{array}{l}\text { Negative } \\
\text { expression }\end{array}$ & $\begin{array}{l}\text { Strong marked } \\
\text { expression }\end{array}$ \\
\hline
\end{tabular}




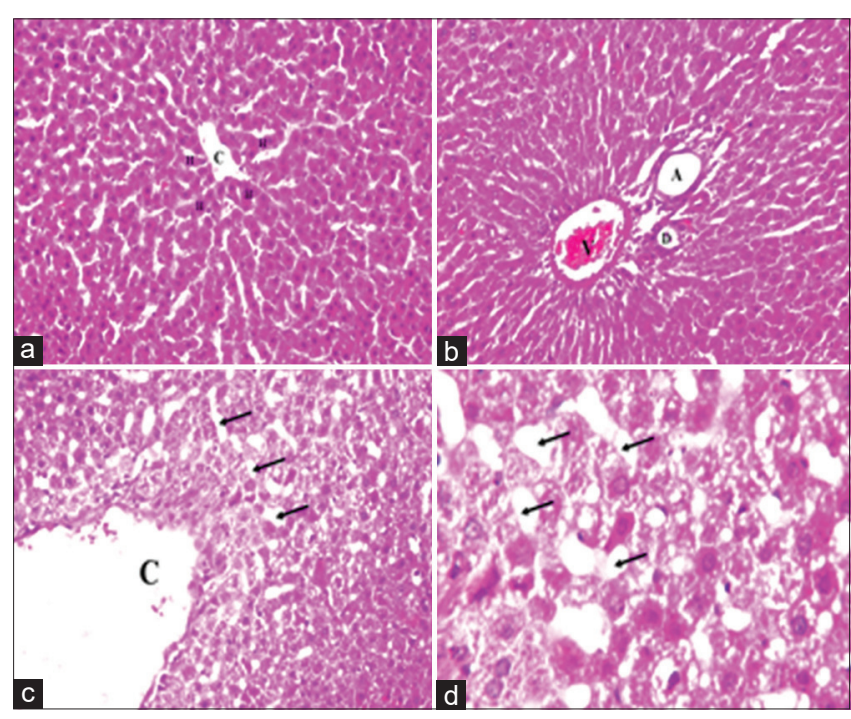

Figure 3: Photomicrographs of sections in the rat liver of control and HSHFD groups. ( $a$ and b) represent the control group with normal histological structure of the central vein (C), Surrounding hepatocyte $(H)$ in the liver parenchyma, the portal vein $(V)$, bile duct $(D)$ and hepatic artery $(A)$ in the portal area (H\&E, $\times 40)$. (c and d) Show sections in rat liver of the HSHFD group. (c) Fatty changes appear in the hepatocytes (arrows) surrounding and adjacent the dilated central vein $(H \& E, \times 40)$. (d) The magnification identifies the fatty changes in the hepatocytes (arrows) (H\&E, $\times 80)$

\section{Discussion}

Chemicals such as NP have been recently studied for their toxic effects on various body organs as well as their oxidative stress-induced DNA damage. The hazardous effects of these EEDs were observed on chronic exposure to various concentrations [26].

In this study, we have investigated the concomitant pathogenic effect resulting from chronic exposure to the synthetic xeno-estrogen NP [27] on HSHFD induced NAFLD.

Previous studies focused on testing the chronic exposure to a high daily dose of NP (180 mg/kg/day) and how it induced NASH together with HSHFD exacerbating liver dysfunction and dyslipidemia [20] and on studying the dose-dependent effect of exposure to various doses $(5,25,125 \mu \mathrm{g} / \mathrm{kg} /$ day $)$ of NP on the expression of $\mathrm{HO}-1$ gene [28].

Sub-chronic exposure to doses as low as $0.02 \mu \mathrm{g} / \mathrm{kg} / \mathrm{day}$ was used to investigate the effect of NP on aggravating NAFLD in rats fed HSHFD [21].

The aim of this work is to investigate whether a low dose of NP for a long period would affect liver function, produce oxidative stress precipitating apoptosis, or will augment all these sequelae only when added to HSHFD.

In this study, four groups were investigated, comprising a group receiving HSHFD to induce NAFLD, another group exposed to a $20 \mu \mathrm{g} / \mathrm{kg}$ BW NP for 60 days, and a third group receiving both. A control group was also included.

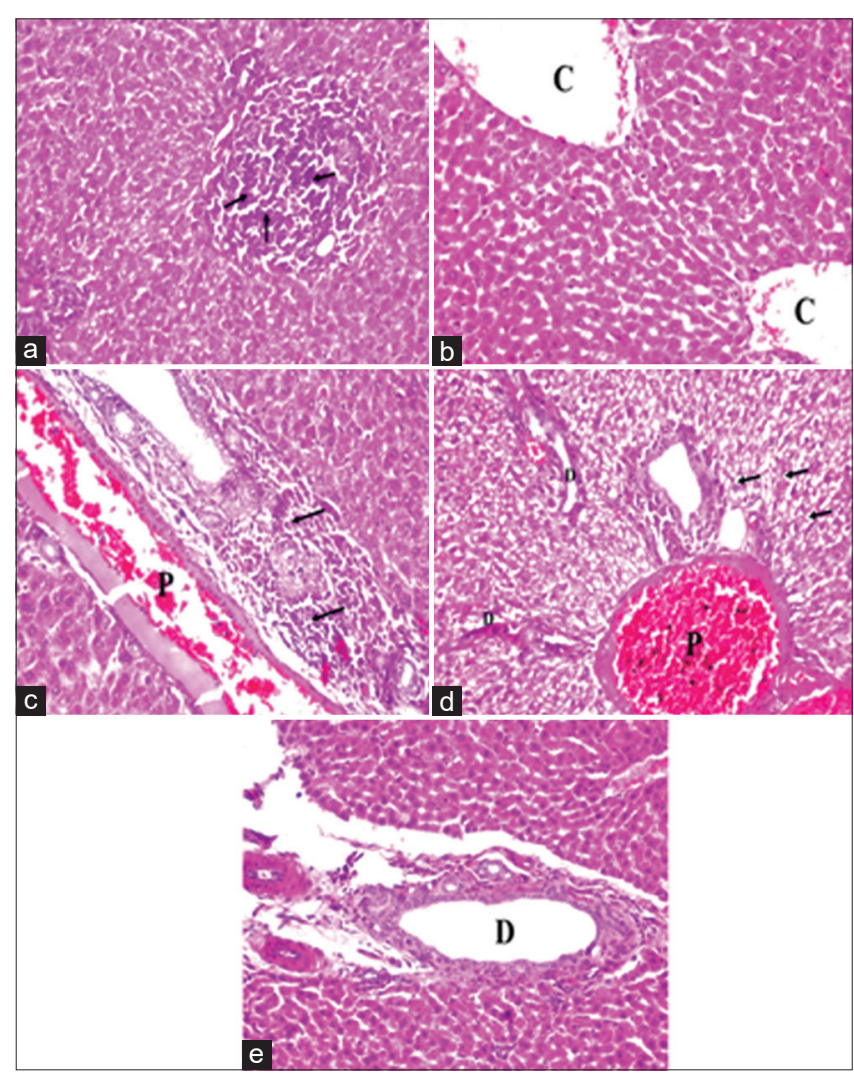

Figure 4: Photomicrographs of sections in the rat liver of NP and NP-HSHFD groups. ( $a$ and b) represent the NP group. (a) There are focal lymphoid cells aggregation in the hepatic parenchyma (arrows) $(H \& E, \times 40)$, (b) shows dilatation in the central veins (C) (H\&E, $\times 40)$. (c-e) Represents sections in rat liver of the NP-HSHFD group, in $C$ there is massive inflammatory cell infiltration in the portal area (arrows) with congestion in the portal vein $(P)(H \& E, \times 40)$. In (d) there are multiple newly formed bile ductules in the portal area (D) with hydropic degeneration in the hepatocytes in the surrounding parenchyma (arrows) and congestion in the portal vein (P) (H\&E, $\times 40$ ). (e) Shows dilatation and hyperplasia in the bile duct of the portal area $(D)(H \& E, \times 40)$

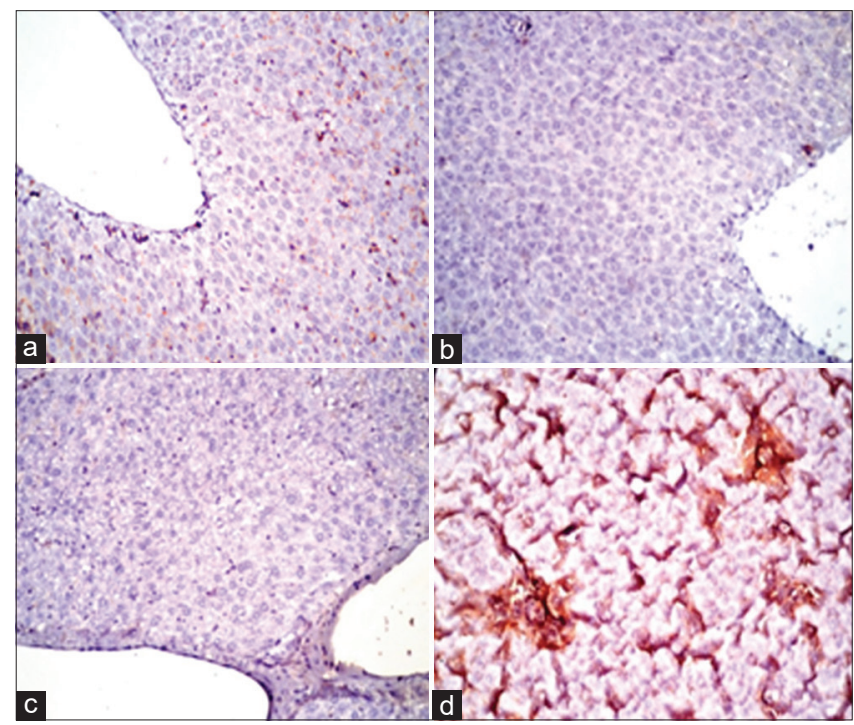

Figure 5: Immuno-histochemical staining of liver sections using caspase-3 antibody. In (a-c) there is negative expression in the control, HSHFD and NP groups respectively. In (d), there is marked expression of caspase-3 protein in the NP-HSHFD group as demonstrated by the distribution and density of brown coloration in tissues (immunostaining, $\times 40$ ) 
Plasma AST and ALT are considered the most sensitive markers for diagnosis of hepatic insult, hence their levels were measured in all groups and compared to normal control levels which are estimated to range between 70-90 U/L for AST and 26-40 U/L for ALT in rats [29].

Herein, we measured plasma ALT and AST levels in all studied groups. A highly statistically significant difference was noted between studied groups compared to control with $p<0.001$.

In previously conducted studies [20], [21] $\mathrm{NP}+\mathrm{HSHFD}$ increased the levels of AST and ALT in rats at doses of $0.02 \mu \mathrm{g} / \mathrm{kg} /$ day and $180 \mathrm{mg} / \mathrm{kg} /$ day respectively.

Another study [30] reported that NP at doses of 15,150 and $1,500 \mu \mathrm{g} / \mathrm{kg} /$ day increased levels of AST and ALT in rats. Another study [28] showed that various doses of NP didn't affect the serum AST or ALT levels. This discrepancy can be due to the difference in animal strains which can result in different reactions to the same EED [31].

AST has a cytosolic and a mitochondrial isoform, with the mitochondrial isoform being much more abundant. Hepatic degeneration due to exposure to hepatotoxic compounds is accompanied by massive mitochondrial injury and precipitates the release of this mitochondrial isoform. The result is a marked increase in AST and an increase of de Ritis ratio in consequence [32].

It is worth mentioning that in our study, plasma AST levels showed the highest levels in the NP + HSHFD group indicating mitochondrial damage and release of the AST isoform, revealing oxidative stress. The NP group also showed a significantly elevated plasma AST compared to the HSHFD group, which emphasizes the role of NP in initiating oxidative stress and hence mitochondrial damage.

Abnormal lipid profile was also recorded among studied groups as evidenced by elevated TG, TC, LDL-C with a statistically significant difference ( $p<0.001$ ) compared to the control group. The dysregulated lipid metabolism was most severe in the NP + HSHFD group. Furthermore, this same group showed the lowest level of serum HDL but was not significantly different from control.

We can conclude from the biochemical tests that NP enhanced the effect of HSHFD in inducing NASH. This was supported by previous studies that demonstrated that a high-sucrose/high-fat diet combined with NP exposure could cause non-alcoholic hepatic steatosis [21].

Studying the microscopic liver morphology showed that the exposure to NP caused pale large nucleolus, cytoplasmic vacuoles, focal lymphoid cell aggregates in the hepatic parenchyma, and dilatation in the central veins. Furthermore, there was massive inflammation and degeneration in the NP + HSHFD. Our data demonstrated that HSHFD causes fatty changes in the liver and these adverse effects are promoted by NP.

The deleterious effects caused by NP reside in its ability to induce oxidative stress by increasing the production of reactive oxygen species (ROS) as hydrogen peroxide. ROS stimulates both the intrinsic and extrinsic apoptotic pathways [33].

Oxidative stress status was investigated by gene expression analysis of the inducible gene Hmox1 [34]. It was revealed that there was an enhanced expression of the Hmox1 gene in the HSHFD group and the group receiving NP + HSHFD with a marked significant difference compared to the control group $(p<0.001)$. The highest expression was noted in the NP + HSHFD group while the NP group did not vary significantly from the control group. This points to the synergistic effect of HSHFD on NP induced oxidative stress. This was confirmed by the immunohistochemistry study which revealed marked expression of caspase-3 (the apoptotic protein) in the NP+HSHFD group.

In a previous study [28], a dose-dependent enhanced expression of Hmox1 gene was noted (at doses of 25 and $125 \mu \mathrm{g} / \mathrm{kg}$ ). Another study [30] tested cytochrome c, caspase-3, caspase-9, as markers of apoptosis (intrinsic pathway) in the liver of NP-treated rats, and elevation was detected with all doses. Also the protein levels of Fas, Fas-L, and caspase-8 (extrinsic pathway).

\section{Conclusion}

Exposure to a daily dose of $20 \mu \mathrm{g} / \mathrm{kg} \mathrm{NP}$ can precipitate $\mathrm{NASH}$, as evidenced by dysregulation of lipid metabolism and the microscopic examination of the liver tissues showing hydropic degeneration, dilatation of central veins, and lymphoid cell infiltration. This toxic effect is augmented by the intake of HSHFD. The mechanism of cytotoxicity resides in the production of ROS which induces mitochondrial damage and hence apoptosis. Marked oxidative stress enhances the expression of the Hmox1 gene. A noticeable expression of caspase-3 confirms apoptosis and hence DNA damage.

\section{References}

1. Ramzan M, Ali I, Matin A. Sonographic assessment of hepatic steatosis (fatty liver) in school children of Dera Ismail Khan city (NWF P) Pakistan. Pak J Nutr. 2009;8(6):797-9. https://doi. org/10.3923/pjn.2009.797.799 
2. Younossi ZM, Koenig AB, Abdelatif D, Fazel $Y$, Henry $L$, Wymer M. Global epidemiology of nonalcoholic fatty liver disease-meta-analytic assessment of prevalence, incidence, and outcomes. Hepatology. 2016;64(1):73-84. https://doi. org/10.1002/hep.28431

\section{PMid:26707365}

3. Marchesini G, Day CP, Dufour JF, Canbay A, Nobili V, Ratziu V, et al. EASL-EASD-EASO Clinical Practice Guidelines for the management of non-alcoholic fatty liver disease. J Hepatol. 2016;64(6):1388-402. https://doi.org/10.1016/j. jhep.2015.11.004

\section{PMid:27062661}

4. Machado MV, Cortez-Pinto H. Non-alcoholic fatty liver disease: What the clinician needs to know. World J Gastroenterol. 2014;20(36):12956-80. https://doi.org/10.3748/wjg.v20.i36.12956 PMid:25278691

5. Yan HM, Gao X, Liu M. Study of the association between nonalcoholic fatty liver disease and metabolic syndrome. Chin $\mathrm{J}$ Diabet. 2006;14:326-8.

6. Jie $\mathrm{Y}$, Pan $\mathrm{W}$, Wenxia $\mathrm{Y}$, Feng $\mathrm{G}$, Liting $\mathrm{H}$, Wenmei $\mathrm{L}$, et al. The effects of gestational and lactational exposure to Nonylphenol on c-Jun, c-fos and learning and memory in hippocampus in male F1 rat. Iran J Basic Med Sci. 2017;20(4):386-91.

PMid:29026496

7. Jie $\mathrm{Y}$, Xuefeng $\mathrm{Y}$, Mengxue $\mathrm{Y}$, Xuesong $\mathrm{Y}$, Jing $\mathrm{Y}$, Yin $\mathrm{T}$, et al. Mechanism of nonylphenol-induced neurotoxicity in F1 rats during sexual maturity. Wien Klin Wochenschr. 2016;128(11-12):42634. https://doi.org/10.1007/s00508-016-0960-6 PMid:26905877

8. Verner MA, Magher T, Haddad S. High concentrations of commonly used drugs can inhibit the in vitro glucuronidation of bisphenol a and nonylphenol in rats. Xenobiotica. 2010;40(2):83-92. https://doi.org/10.3109/00498250903383334 PMid:19916736

9. Kazemi S, Feizi F, Aghapour F, Joorsaraee GA, Moghadamnia AA. Histopathology and histomorphometric investigation of bisphenol a and nonylphenol on the male rat reproductive system. N Am J Med Sci. 2016;8(5):215-21. https:// doi.org/10.4103/1947-2714.183012

PMid:27298816

10. Jie $X$, Yang W, Jie Y, Fan QY, Liu XY, Yan L, et al. Immune effects of nonylphenol on offspring of rats exposed during pregnancy. Hum Ecol Risk Assess. 2010;16(2):444-52. https:// doi.org/10.1080/10807031003670485

11. Couderc M, Gandar A, Kamari A, Allain Y, Zalouk-Vergnoux A, Herrenknecht $C$, et al. Neurodevelopmental and behavioral effects of nonylphenol exposure during gestational and breastfeeding period on F1 rats. Neurotoxicology. 2014;44:237-49. https://doi.org/10.1016/j.neuro.2014.07.002 PMid:25058900

12. Lee HA, Park SH, Hong YS, Ha EH, Park H. The effect of exposure to persistent organic pollutants on metabolic health among KOREAN children during a 1-year follow-up. Int J Environ Res Public Health. 2016;13(3):E270. https://doi.org/10.3390/ ijerph13030270

PMid:26938545

13. Kourouma A, Keita H, Duan P, Quan C, Bilivogui KK, Qi S, et al. Effects of 4-nonylphenol on oxidant/antioxidant balance system inducing hepatic steatosis in male rat. Toxicol Rep. 2015;2:1423-33. https://doi.org/10.1016/j.toxrep.2015.10.006 PMid:28962484

14. Tran V, Tindula G, Huen K, Bradman A, Harley K, Kogut K, et al. Prenatal phthalate exposure and 8-isoprostane among MexicanAmerican children with high prevalence of obesity. J Dev Orig Health Dis. 2017;8(2):196-205. https://doi.org/10.1017/

\section{s2040174416000763}

PMid:28031075

15. Geng S, Wang S, Zhu W, Xie C, Li X, Wu J, et al. Curcumin attenuates BPA-induced insulin resistance in HepG2 cells through suppression of JNK/p38 pathways. Toxicol Lett. 2017;272:75-83. https://doi.org/10.1016/j.toxlet.2017.03.011 PMid:28300666

16. Saponaro C, Gaggini M, Gastaldelli A. Nonalcoholic fatty liver disease and Type 2 diabetes: Common pathophysiologic mechanisms. Curr Diab Rep. 2015;15(6):607. https://doi. org/10.1007/s11892-015-0607-4 PMid:25894944

17. Korkmaz A, Ahbab MA, Kolankaya D, Barlas N. Influence of vitamin $\mathrm{C}$ on bisphenol $\mathrm{A}$, nonylphenol and octylphenol induced oxidative damages in liver of male rats. Food Chem Toxicol. 2010;48(10):2865e-71. https://doi.org/10.1016/j.fct.2010.07.019 PMid:20643179

18. Daidoji $\mathrm{T}$, Inoue $\mathrm{H}$, Kato $\mathrm{S}$, Yokota $\mathrm{H}$. Glucuronidation and excretion of nonylphenol in perfused rat liver. Drug Metab Dispos. 2003;31(8):993e-8. https://doi.org/10.1124/dmd.31.8.993 PMid: 12867487

19. Jubendradass R, D'Cruz SC, Mathur PP. Short-term exposure to nonylphenol induces pancreatic oxidative stress and alters liver glucose metabolism in adult female rats. J Biochem Mol Toxicol. 2011;25(2):77e-83. https://doi.org/10.1002/jbt.20361 PMid:21472897

20. Yu J, Yang X, Luo Y, Yang X, Yang M, Yang J, et al. Adverse effects of chronic exposure to nonylphenol on nonalcoholic fatty liver disease in male rats. PLoS One. 2017;12(7):e0180218. https://doi.org/10.1371/journal.pone.0180218 PMid:28686624

21. $Y u$ J, Yang $X$, Yang $X$, Yang $M$, Wang $P$, Yang $Y$, et al Nonylphenol aggravates nonalcoholic fatty liver disease in high sucrose-high fat diet-treated rat. Sci Rep. 2018;8:3232. https:// doi.org/10.1038/s41598-018-21725-y

22. Bancroft JD, Stevens A. Theory and Practice of Histological Techniques. $4^{\text {th }}$ ed. New York: Churchill Livingstone; 1996.

23. Mohamed AK, Magdy M. Caspase 3 role and immunohistochemical expression in assessment of apoptosis as a feature of H1N1 vaccine-caused Drug-Induced Liver Injury (DILI). Electronic Physician. 2017;9(5):4261-73. https://doi. org/10.19082/4261

PMid:28713494

24. Snedecor GM, Cochran WG. Statistical Methods. $7^{\text {th }}$ ed. Ames: lowa State Univ Press; 1980. p. 325-330.

25. Härdle W, Simar L. Applied Multivariate Statistical Analysis. $2^{\text {nd }}$ ed. Berlin, Germany: Springer. 2007. p. 420.

26. Lin X, Ni Y, Kokot S. An electrochemical DNA-sensor developed with the use of methylene blue as a redox indicator for the detection of DNA damage induced by endocrine-disrupting compounds. Anal Chim Acta. 2015;867:29-37. https://doi. org/10.1016/j.aca.2015.02.050

PMid:25813025

27. Ben-Jonathan N, Steinmetz R. Xenoestrogens: The emerging story of bisphenol a. Trends Endocrinol Metab 1998;9(3):124e-8. https://doi.org/10.1016/s1043-2760(98)00029-0 PMid: 18406253

28. Kazemi S, Kani SN, Ghasemi-Kasman M, Aghapour F, Khorasani H, Moghadamnia AA. Nonylphenol induces liver toxicity and oxidative stress in rat. Biochem Biophys Res Commun. 2016;479(1):17e-21. https://doi.org/10.1016/j. bbrc.2016.08.164 PMid:27590577

29. Pari L, Amali DR. Protective role of tetrahydrocurcumin 
(THC) an active principle of turmeric on chloroquine induced hepatotoxicity in rats. J Pharm. 2005;8(1):115-23.

PMid:15946605

30. Jubendradass R, D'Cruz SC, Rani SA, Mathur PP. Nonylphenol induces apoptosis via mitochondria-and Fas mediated pathways in the liver of adult male rat. Regul Toxicol Pharmacol. 2012;62(3):405-11. https://doi.org/10.1016/j.yrtph.2012.01.004

31. Richter CA, Birnbaum LS, Farabollini F, Newbold RR, Rubin BS, Talsness CE, et al. In vivo effects of bisphenol a in laboratory rodent studies. Reprod Toxicol. 2007;24(2):199-224. https://doi. org/10.1016/j.reprotox.2007.06.004 PMid: 17683900

32. Sepulveda J. Challenges in routine clinical chemistry analysis: Proteins and enzymes. In: Accurate Results in the Clinical
Laboratory. A Guide to Error Detection and Correction Netherlands: Elsevier; 2013. p. 131-48. https://doi.org/10.1016/ b978-0-12-415783-5.00009-8

33. Noorimotlagh Z, Mirzaee SA, Ahmadi M, Jaafarzadeh N, Rahimd F. The possible DNA damage induced by environmental organic compounds: The case of Nonylphenol. Ecotoxicol Environ Saf. 2018;158:171-81. https://doi.org/10.1016/j.ecoenv.2018.04.023 PMid:29684747

34. Lia R, Zhaoa L, Zhanga L, Chena M, Donga C, Caib Z. DNA damage and repair, oxidative stress and metabolism biomarker responses in lungs of rats exposed to ambient atmospheric 1-nitropyrene. Environ Toxicol Pharmacol. 2017;54:14-20. https://doi.org/10.1016/j.etap.2017.06.009

PMid:28668703 